\title{
Edukasi Penanganan Adiksi Remaja di Sekolah Melalui Pendekatan Kesehatan dan Agama
}

\author{
Yanuar Fahrizal ${ }^{1}$, Fahmi Irfanudin², Syahruramdhani ${ }^{2}$ \\ 1,2 Universitas Muhammadiyah Yogyakarta
}

\begin{tabular}{|c|c|}
\hline Article History & ABSTRACT \\
\hline $\begin{array}{l}\text { Received 01.08.2019 } \\
\text { Received in revised form } \\
01.10 .2019 \\
\text { Accepted } 04.10 .2019 \\
\text { Available online 28.10.2019 }\end{array}$ & $\begin{array}{l}\text { EDUCATION OF ADOLESCENT ADDICTION TREATMENT WITH HEALTH } \\
\text { AND RELIGIOUS EDUCATION APPROACHES AT SCHOOL. Smoking, drugs, } \\
\text { pornography and video game addiction cases are iceberg mountain phenomenon } \\
\text { which the cases are seen only as small part from fully part of the cases particularly } \\
\text { in adolescent. This effects to health status of adolescent involve physics, mental, } \\
\text { spiritual and social. Smoking, drugs, pornography and video game behaviour as } \\
\text { abnormal behaviour on adolescent are an immature response from stress that } \\
\text { happened in developing phase of adolescent. As the effort to prevent the } \\
\text { incidence of adolescent abnormal behaviour and to increase mental health } \\
\text { promotion especially on adolescent and teachers is needed preventive and pro- } \\
\text { motive program with adolescent addiction education program. This program was } \\
\text { conducted to teachers of MTs Muhammadiyah Kasihan because the teachers have } \\
\text { much interaction with adolescent. This community service program was } \\
\text { conducted with various method such as screening, preparation, teaching, } \\
\text { empowering and evaluation. The result showed that the rate of teacher's } \\
\text { knowledge before conducting the education program is low or bad with score } 48.1 \\
\text { and after conducting the education program increased to fair or enough with } \\
\text { score } 61.45 \text {. This community service program also developed module book about } \\
\text { adolescent addiction treatment with health and religious education approaches. }\end{array}$ \\
\hline & KEYWORDS: Addiction, Adolescent, Mental Health. \\
\hline
\end{tabular}

DOI: $10.30653 / 002.201943 .184$

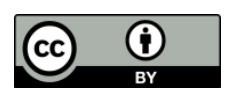

This is an open access article distributed under the terms of the Creative Commons Attribution 4.0 International License, which permits unrestricted use, distribution, and reproduction in any medium, provided the original work is properly cited. ๑ 2019 Yanuar Fahrizal, Fahmi Irfanudin, Syahruramdhani.

\section{PENDAHULUAN}

Kasus adiksi rokok, NAPZA, pornografi dan video game merupakan suatu fenomena gunung es, dimana kasus yang tampak hanya sebagian kecil dari keseluruhan kasus yang ada terutama pada remaja. Secara global pada tahun 2010 diperkirakan sebanyak 153-300 juta orang dengan usia 15-64 tahun (3,4-6,6\% dari populasi kelompok umur di dunia) menggunakan NAPZA pada satu tahun terakhir (UNODC, 2012).

${ }^{1}$ Corresponding author: Program Studi Ilmu Keperawatan, FKIK Universitas Muhammadiyah Yogyakarta; Jl. Brawijaya, Kasihan, Bantul, Yogyakarta; Email: yanuarfahrizal89@gmail.com 
Sebanyak 15,5-38,6 juta merupakan pengguna obat-obatan yang terdiri dari orang yang ketergantungan obat dan gangguan penyalahgunaan obat. Badan Narkotika Nasional pada tahun 2014 menyebutkan bahwa jumlah penyalahgunaan narkoba di Indonesia sebanyak 3,8-4,1 juta orang atau sekitar 2,1\%-2,25\% dari total seluruh penduduk Indonesia (BNN, 2014). Yogyakarta merupakan kota pelajar dan kota wisata sehingga banyak orang datang ke kota ini. Hal tersebut membuat Yogyakarta menjadi rentan dalam masuk dan berkembangnya penyebaran NAPZA (Pemerintah Provinsi Daerah Istimewa Yogyakarta, 2010). Selain masalah adiksi NAPZA, remaja juga sering mengalami masalah adiksi video game.

Remaja yang adiksi video game dapat bermain video game selama 20-23 jam dalam seminggu dan menimbulkan masalah sosial (Guno, 2018). Remaja yang menghabiskan sebagian besar waktunya untuk bermain video game tentu akan menganggu dalam kehidupan sehari-harinya seperti penentuan prioritas kegiatan. Masalah lain yang banyak dikalangan remaja adalah masalah pornografi. Kasus melihat pornografi yang terjadi sebanyak $79 \%$ dirumah, sekolah $9 \%$, rumah teman $5 \%$ dan lainnya $5 \% .1$ dari 5 orang anak pernah mengakses website porno. Kejadian meningkat pada usia 14-15 tahun dan proporsi $87 \%$ laki-laki dan $31 \%$ perempuan melihat pornografi (Therapy Associates, 2013). Permasalahan adiksi NAPZA, video game dan pornografi dapat menyebabkan perubahan status kesehatan seseorang.

Kesehatan merupakan suatu keadaan sehat, baik secara fisik, mental, spritual maupun sosial yang memungkinkan setiap orang untuk hidup produktif secara sosial dan ekonomis (Undang-Undang RI No. 36 tentang kesehatan tahun 2009). Didalam makna kesehatan secara umum terdapat bagian yang tidak dapat dipisahkan yaitu kesehatan jiwa. Kesehatan jiwa merupakan kondisi dimana seorang individu dapat berkembang secara fisik, mental, spiritual, dan sosial sehingga individu tersebut menyadari kemampuan sendiri, dapat mengatasi tekanan, dapat bekerja secara produktif, dan mampu memberikan kontribusi untuk komunitasnya. (Undang-Undang Kesehatan Jiwa No.18 Tahun 2014). Untuk dapat mencapai derajat kesehatan optimal tentu diperlukan suatu pengetahuan yang benar yang dapat menuntun pada perilaku yang sehat dan benar.

Di Desa Bangunjiwo terdapat sekolah MTs Muhammadiyah Kasihan yang mulai berdiri sejak 1 Agustus 1982. Pendirian MTs Muhammadiyah berfokus untuk memberikan layanan pendidikan lanjutan bagi siswa-siswa lulusan SD yang berada disekitar madrasah. Siswa yang bersekolah di MTs Muhammadiyah Kasihan termasuk ke dalam rentang usia remaja yaitu berusia antara 13-16 tahun. Pada usia tersebut remaja sering mengalami permasalahan kenakalan remaja berupa perilaku merokok, penyalahgunaan narkoba, adiksi pornografi dan adiksi video game. Berdasarkan pengkajian yang dilakukan kepada guru MTs Muhammadiyah kasihan, masalah tersebut dapat terjadi karena banyak faktor salah satunya adalah banyaknya role model yang buruk di lingkungannya seperti perilaku merokok di tempat umum. Faktor lain juga karena pergaulan remaja yang bebas dan kemudahan akses ke internet dan kurangnya pengawasan dari orang dewasa menjadikan remaja ini rentan melakukan perilaku pornografi dan bermain video game secara berlebihan. Perilaku merokok, penyalahgunaan NAPZA, bermain video game berlebihan dan menonton pornografi sebagai bentuk kenakalan remaja merupakan suatu respon immature dari stress yang 
terjadi pada tahap perkembangan remaja (Lee, 2011). Pihak sekolah (guru) tentu memiliki strategi dalam mengantisipasi permasalahan ini.

Guru merupakan orang yang paling sering berinteraksi dengan siswa remaja di sekolah. Guru sekolah MTs Muhammadiyah Kasihan berdasarkan hasil pengkajian yang dilakukan terlihat masih kurang dalam hal pengetahuan terkait penanganan perilaku adiksi (merokok, narkoba, pornografi dan video game) dan belum pernah mendapatkan edukasi terkait masalah tersebut. Program peningkatan kualitas hidup remaja serta program pencegahan secara khusus pada bahaya rokok, narkoba, pornografi dan video game masih belum pernah dilakukan karena keterbatasan waktu, biaya dan sumber daya. Hal ini penting karena sangat berkaitan dengan kesehatan remaja dimana kesehatan tidak hanya berfokus kepada kesehatan secara fisik saja tetapi juga kesehatan jiwa seperti tumbuh kembang remaja yang sehat.

Berdasarkan urian tersebut dapat diambil kesimpulan bahwa remaja di lingkungan sekolah MTs Muhammadiyah Kasihan rentan terjadi permasalahan adiksi rokok, adiksi NAPZA, adiksi pornografi dan adiksi video game serta masih rendahnya pengetahuan guru sekolah terkait penanganan masalah tersebut. Melihat hal itu, pengabdi bermaksud melakukan pengabdian masyarakat dengan cara melakukan edukasi penanganan adiksi remaja di sekolah dengan pendekatan kesehatan dan agama kepada guru dan karyawan sekolah MTs Muhammadiyah Kasihan.

\section{METODE PELAKSANAAN}

Kegiatan ini adalah upaya preventif dan promotif yang bertujuan untuk meningkatkan pengetahuan guru dan karyawan tentang penanganan permasalah remaja seperti adiksi rokok, NAPZA, pornografi dan video game berlebih serta mencegah terjadinya permasalahan kenakalan remaja adiksi melalui 5 tahapan yang meliputi screening, preparation, teaching, empowering, evaluation yang dapat dilihat pada Gambar 1.

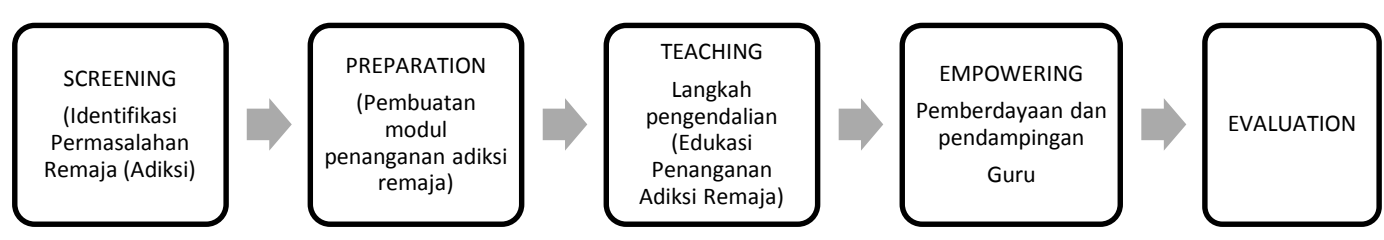

Gambar 1. Langkah Edukasi Penanganan Adiksi Remaja

1) Screening. Kegiatan dilakukan dengan cara mengidentifikasi permasalahan yang dihadapi sekolah serta penyebabnya terkait dengan kenakalan remaja.

2) Preparation. Pada tahap ini dilakukan persiapan berupa pengurusan kerja sama dan penyusunan bahan edukasi dan pembuatan buku/ modul.

3) Teaching. Penyuluhan/ edukasi penanganan adiksi pada remaja dengan pendekatan kesehatan dan agama. Pada tahap ini juga dilakukan pre dan post test untuk melihat kemajuan dari edukasi yang dilakukan.

4) Empowering. Kegiatan ini berupa pemberdayaan guru dengan melakukan edukasi mandiri kepada siswa tentang penanganan masalah adiksi remaja.

5) Evaluation. Kegiatan ini dilakukan bersama guru dan rencana tindak lanjut. 


\section{HASIL DAN PEMBAHASAN}

Kegiatan Pengabdian dilakukan pada bulan Januari-Maret 2019 yang terdiri dari beberapa kegiatan.

\section{Screening}

Kegiatan screening dilakukan dengan cara melakukan pengkajian awal permasalahan remaja di MTs Muhammadiyah Kasihan melalui wawancara kepada guru mata pelajaran, kepala sekolah dan guru bimbingan konseling. Hasil wawancara didapatkan mayoritas siswa yang bersekolah berasal dari keluarga menengah kebawah dan kurang mendapatkan role model perilaku hidup sehat. Siswa sering kali terpapar orang dewasa yang merokok disembarang tempat. Permasalahan lain adalah sebagian besar siswa sudah memiliki smartphone yang terkoneksi dengan internet. Hal ini sebenarnya hal yang baik apabila dilakukan pengawasan dalam hal penggunaannya, namun seringkali orang tua tidak melakukan pengawasan terhadap penggunaan smartphone anaknya. Pihak sekolah juga menceritakan bahwa guru dan karyawan MTs Muhammadiyah Kasihan belum pernah mendapatkan penyuluhan kesehatan jiwa terkait pengananan adiksi pada remaja. Pengkajian yang dilakukan masih berupa pengkajian secara kualitatif kepada guru dan karyan karena sampai saat ini masih belum ada instrument yang cukup sensitif untuk digunakan di lingkup sekolah sebagai pengkaji universal untuk mengidentifikasi risiko, menginformasikan rencana tindakan dan menyediakan proses monitoring (Morrison \& Rollenhagen, 2017).

\section{Preparation}

Pada tahap ini dilakukan pengurusan kerja sama antara pihak kampus Universitas Muhammadiyah Yogyakarta dengan MTs Muhammadiyah Kasihan untuk dilakukan kegiatan pengabdian masyarakat berupa penyuluhan kesehatan. Pengabdi juga melakukan kerja sama dengan LP3M UMY untuk pengajuan dana hibah pengabdian masyarakat untuk mendukung program pengabdian yang dilakukan. Selain hal itu juga dilakukan persiapan berupa penyusunan bahan penyuluhan dan pembuatan pedoman edukasi adiksi remaja dengan pendekatan kesehatan dan agama berupa buku modul. Pembuatan buku dilakukan agar setelah kegiatan ini selesai dilakukan, guru maupun karyawan masih dapat membaca dan mendapatkan informasi terkait penanganan adiksi remaja di sekolah. Keberhasilan sebuah pengabdian masyrakat ditentukan oleh organisasi komunitas, pendanaan untuk mendampingi pengembangan kerja sama dan peluang dari jaringan dengan komunitas lain (Adamson \& Bromiley, 2008). Keterbukaan dan sikap penerimaan dari komunitas menunjukkan bahwa kegiatan yang dilakukan dapat bersifat mutualisme atau saling menguntungkan kedua belah pihak.

\section{Teaching}

Pada tahap ini dilakukan implementasi berupa edukasi penanganan adiksi remaja di sekolah dengan pendekatan kesehatan dan agama pada bulan Februari 2019. Peserta yang mengikuti kegiatan ini adalah guru dan karyawan MTs Muhammadiyah Kasihan yang bervariasi karakterisiknya. Hasil distribusi gambaran demografis peserta dapat dilihat pada Tabel 1 . 
Tabel 1. Gambaran Demografis Peserta Edukasi $(n=20)$

\begin{tabular}{llrc}
\hline Karakteristik & & Jumlah & Persentase (\%) \\
\hline Jenis Kelamin & Laki-laki & 9 & 45 \\
Usia & Perempuan & 11 & 55 \\
\multirow{3}{*}{ Pendidikan } & $\leq 40$ & 5 & 25 \\
& $>40$ tahun & 15 & 75 \\
& SMA & 1 & 5 \\
& Diploma & 2 & 10 \\
Lama Bekerja & Sarjana & 16 & 80 \\
& Magister & 1 & 5 \\
& 0-5 tahun & 7 & 35 \\
& 6-10 tahun & 2 & 10 \\
& $11-15$ tahun & 3 & 15 \\
& $16-20$ tahun & 1 & 5 \\
& $21-25$ tahun & 3 & 15 \\
& $>25$ tahun & 4 & 20 \\
\hline
\end{tabular}

Berdasarkan Tabel 1, tampak bahwa mayoritas peserta kegiatan edukasi ini adalah berjenis kelamin perempuan sejumlah 11 orang $(55 \%)$, usia mayoritas $<40$ tahun sejumlah 15 orang $(75 \%)$, pendidikan terakhir sarjana sebanyak 16 orang $(80 \%)$ dan lama bekerja paling banyak adalah 0-5 tahun (35\%).

Kegiatan ini dilaksanakan terdiri dari tiga sesi dimana setiap sesinya membahas satu permasalahan adiksi seperti adiksi rokok dan NAPZA, adiksi video game dan adiksi pornografi. Setiap permasalahan dipaparkan dalam tiga tinjauan yaitu tinjauan kesehatan jiwa, biomedis dan agama Islam. Hal ini dilakukan karena pengabdi berupaya memberikan pemahaman kepada guru dan karyawan secara menyeluruh. Diharapkan guru dan karyawan tidak hanya tahu tentang masalah yang sering dihadapi oleh remaja tetapi juga memahami proses terjadi permasalahan adiksi pada remaja baik dari segi psikologis/ kesehatan jiwa maupun biomedis seperti perubahan neurotransmitter pada otak remaja serta mengetahui pedoman yang berasal dari agama Islam.

Materi edukasi yang diberikan kepada peserta antara lain: Profil kesehatan jiwa, kesehatan jiwa remaja, Rokok \& narkoba dalam perspektif Islam, Aspek biomed rokok dan narkoba, Rokok dan narkoba dalam kesehatan jiwa dan penanganannya, Pornografi dalam perspektif Islam, Aspek biomed adiksi pornografi, Adiksi pornografi dalam kesehatan jiwa dan penanganannya, Video game dalam perspektif Islam, Aspek biomed adiksi video game, Adiksi video game dalam kesehatan jiwa dan penanganannya.

Sebelum dilakukan edukasi penanganan adiksi remaja di sekolah dengan pendekatan kesehatan dan agama, terlebih dahulu dilakukan pengukuran pengetahuan (pre) terlebih dahulu pada 20 peserta dan setelah selesai kegiatan juga dilakukan pengukuran kembali (post) namun hanya pada 16 peserta karena terdapat 4 peserta yang sudah pulang terlebih dahulu karena ada kepentingan yang lain diluar sekolah. Hasil pengukuran pengetahuan dapat dilihat pada Tabel 2 . 
Tabel 2. Gambaran Hasil Pengukuran Pengetahuan (n=20)

\begin{tabular}{cccc}
\hline No Peserta & Nilai Pre & Nilai Post & Perubahan nilai \\
\hline 1 & 6,0 & 5,6 & $-0,4$ \\
2 & 6,0 & 6,1 & 0,1 \\
3 & 5,0 & 6,1 & 1,1 \\
4 & 5,3 & 4,6 & $-0,7$ \\
5 & 5,3 & 4,6 & $-0,7$ \\
6 & 4,0 & 6,1 & 2,1 \\
7 & 3,6 & 3,6 & 0,0 \\
8 & 4,3 & 5,0 & 0,7 \\
9 & 5,0 & 5,6 & 0,6 \\
10 & 3,6 & 5,6 & 2,0 \\
11 & 5,0 & 4,3 & $-0,7$ \\
12 & 5,3 & 6,6 & 1,3 \\
13 & 6,0 & 7,6 & 1,6 \\
14 & 4,6 & 9,0 & 4,4 \\
15 & 3,6 & 8,6 & 5,0 \\
16 & 6,1 & 5,3 & $-0,8$ \\
17 & 3,6 & - & - \\
18 & 4,3 & - & - \\
19 & 5,6 & - & - \\
20 & 4,0 & - & - \\
\hline
\end{tabular}

Berdasarkan Tabel 2 dapat diketahui bahwa mayoritas peserta edukasi penanganan adiksi remaja mengalami peningkatan pengetahuan, dimana perubahan terbesar pada peserta nomor 15 dengan perubahan nilai sebanyak 5 poin. Keberhasilan kegiatan ini terlihat dari sejumlah $75 \%$ peserta mengalami peningkatan pengetahuan tentang penanganan adiksi pada remaja. Meskipun mayoritas terjadi peningkatan pengetahuan yang ditandai dengan peningkatan nilai post test namun masih terdapat 5 orang yang hasil post test nya justru menurun. Hal ini dimungkinkan karena mayoritas peserta sudah berusia lebih dari 40 tahun dan kegiatan dilakukan dalam 1 hari sehingga berpengaruh pada konsentrasi peserta.

\section{Empowering}

Pada tahapan keempat ini, pengabdi memberikan kesempatan dan pendampingan kepada guru untuk melakukan penyuluhan kepada siswa MTs Muhammadiyah Kasihan tentang remaja sehat dan pencegahan adiksi NAPZA, video gaming dan pornografi pada remaja. Dalam tahap ini guru berlatih keterampilan seperti yang sudah diajarkan oleh pengabdi. Pihak sekolah juga selaku pengelola memberikan fasilitasi kepada guru maupun karyawan untuk mengimplementasikan ilmu yang sudah diajarkan selama proses pelatihan. Proses pemberdayaan yang dilakukan meliputi pengaktifan komunitas, membangun kompetensi, melatih keterampilan dan menciptakan lingkungan yang mendukung (Kasmel \& Andersen, 2011).

\section{Evaluation}

Kegiatan evaluasi dilakukan pada bulan Maret dan April dengan cara melakukan wawancara secara kualitatif kepada guru dan karyawan yang telah mengikuti kegiatan pengabdian ini. Hasil dari evaluasi menunjukkan bahwa guru sebagian besar sudah merasa lebih percaya diri dalam melakukan edukasi bahaya adiksi pada remaja. Namun, guru juga mengungkapkan masih merasa kurang dalam hal pemahaman terkait 
permasalahan kesehatan remaja yang lainnya dan berharap kegiatan ini dapat dilakukan secara berkelanjutan agar pengetahuan guru dan karyawan selalu terbarukan melalui kegiatan penyuluhan kesehatan.

Notoatmodjo (2015) menyebutkan bahwa pengetahuan adalah suatu hasil tahu dari manusia yang hanya untuk sekadar menjawab pertanyaan. Pengetahuan hanya dapat menjawab apa sesuatu itu. Pengetahuan pada dasarnya terdiri dari sejumlah fakta dan teori yang memungkinkan seseorang untuk membantu menyelesaikan masalahnya. Pengetahuan didapat dari pengalaman langsung maupun melalui pengalaman orang lain. Pengetahuan adalah suatu keterampilan dan keahlian yang diperoleh seseorang melalui pengalaman dan pendidikan. Pemahaman teoritis atau praktis dari suatu objek. Pengetahuan melibatkan proses kognitif yang kompleks meliputi persepsi, pembelajaran, komunikasi, asosiasi dan penalaran. Pengkategorian tingkat pengetahuan terbagi menjadi 3 tingkat, yaitu:

1) Pengetahuan baik : benar $76 \%-100 \%$

2) Pengetahuan sedang/cukup : benar $56 \%-75 \%$

3) Pengetahuan kurang/buruk : benar 0 - $55 \%$

Rata-rata pengetahuan peserta sebelum diberikan edukasi penanganan adiksi remaja di sekolah adalah kurang/atau buruk dengan nilai rata-rata 48,1 dan setelah diberikan edukasi rata-rata pengetahuan peserta meningkat menjadi sedang/cukup dengan nilai rata-rata 61,45. Pemberian edukasi merupakan salah satu strategi untuk dapat merubah perilaku seseorang terkait permasalahan adiksi (Rodda, Booth, Vacaru, Knaebe, \& Hodgins, 2018).

Penyebab remaja mengalami penyalahgunaan NAPZA salah satunya karena kurangnya informasi dan Pendidikan terkait penyalahgunaan NAPZA di keluarga dan komunitas (Fahrizal, Hamid, \& Daulima, 2018). Pemberian edukasi terkait penanganan adiksi pada guru merupakan hal yang sesuai karena dengan guru mengetahui penanganan adiksi dapat melakukan tindakan yang diperlukan kepada para murid yang memiliki permasalahan terkait adiksi. Anak yang mengalami penyalahgunaan NAPZA sangat perlu mendapatkan pendampingan baik dengan cara konseling maupun tindakan terapi kognitif perilaku yang dilakukan oleh orang yang sudah terlatih (Haryati, 2016).

Siswa di sekolah merupakan kelompok yang rentan mengalami kekerasan seksual baik dari orang dewasa maupun temannya (Rumble et al., 2018). Sekolah merupakan tempat kedua dimana kejadian menonton pornografi paling sering dilakukan oleh siswa (Allen, 2016). Penyebab siswa terkena pornografi di sekolah karena terpengaruh teman sebaya dan lingkungannya (Kementerian Pendidikan dan Kebudayaan, 2017). Adiksi pornografi memiliki efek buruk pada perkembangan seksual dan fungsi seksual remaja (de Alarcón, Iglesia, Casado, \& Montejo, 2019).

\section{SIMPULAN}

Edukasi penanganan adiksi remaja dengan menggunakan pendekatan kesehatan dan agama mampu meningkatkan tingkat pengetahuan dan pemahaman guru dan karyawan MTs Muhammadiyah Kasihan, Bantul. 


\section{REFERENSI}

Adamson, D., \& Bromiley, R. (2008). Community empowerment in practice. Lessons from communities first. York, UK: Joseph Rowntree Foundation.

Allen, T. (2016). Digital Pornography Addiction: What you need to know and where to find help. Colorado: Focus on the Family.

BNN. (2014). Laporan akhir survei nasional perkembangan penyalahguna narkoba tahun anggaran 2014. Jakarta: Badan Narkotika Nasional.

de Alarcón, R., de la Iglesia, J. I., Casado, N. M., \& Montejo, A. L. (2019). Online porn addiction: What we know and what we don't-A systematic review. Journal of Clinical Medicine, 8(1), 91. doi: 10.3390/jcm8010091

Fahrizal, Y., Hamid, A. Y. S., \& Daulima, N. H. C. (2018). The life during adolescence in the perspective of ex-drug users in Indonesia. Enfermeria Clinica, 28, 316-320.

Guno, D. C. (2018). Gambaran perilaku kecanduan game online pada anak usia sekolah di wilayah kecamatan Magetan. Surakarta: Universitas Muhammadiyah Surakarta.

Haryati, T. (2016). Child abuse and addiction. Pyrex Journal of Psychology and Counseling, 2(1), $1-4$.

Kasmel, A., \& Andersen, P. T. (2011). Measurement of community empowerment in three community programs in Rapla ( Estonia). International Journal of Environmental Research and Public Health, 8, 799-817. doi: 10.3390/ijerph8030799

Kementerian Pendidikan dan Kebudayaan. (2017). Mendampingi anak menghadapi bahaya pornografi. Jakarta: Kementerian Pendidikan dan Kebudayaan.

Lee, T. Y. (2011). Construction of an integrated positive youth development conceptual framework for the prevention of the use of psychotropic drugs among adolescents. The Scientific World Journal, 11, 2403-2417. doi: 10.1100/2011/315870

Morrison, J. Q., \& Rollenhagen, J. L. (2017). Commentary: Universal Screening for social , emotional and behavioral risk in schools using protective factors. Journal of Psychology \& Psychotherapy, 7(4), 1-4. doi: 10.4172/2161-0487.1000314

Notoatmodjo. (2015). Metodologi penelitian kesehatan. Jakarta: Rineka Cipta.

Pemerintah Provinsi Daerah Istimewa Yogyakarta. (2010). Peraturan Daerah Provinsi Daerah Istimewa Yogyakarta Nomor 13 Tahun 2010.

Rodda, S. N., Booth, N., Vacaru, M., Knaebe, B., \& Hodgins, D. C. (2018). Behaviour change strategies for internet, pornography and gaming addiction: A taxonomy and content analysis of professional and consumer websites. Computers in Human Behavior, 84, 467-476. doi: 10.1016/j.chb.2018.03.021

Rumble, L., Febrianto, R. F., Larasati, M. N., Hamilton, C., Mathews, B., \& Dunne, M. P. (2018). Childhood sexual violence in Indonesia: a systematic review. Trauma, Violence, E Abuse, 1-16.doi: 10.1177/1524838018767932

Therapy Associates. (2013). Navigating pornography addiction: a guide for parents. St. George, Utah: Therapy Associates.

UNODC. (2012). World drug report 2012. New York: United Nations Publications.

Undang-Undang RI No. 36 tentang Kesehatan Tahun 2009.

Undang-Undang RI No.18 tentang Kesehatan Jiwa Tahun 2014. 